Check for updates

Cite this: RSC Adv., 2017, 7, 41479

Received 5th July 2017

Accepted 14th August 2017

DOI: $10.1039 / \mathrm{c} 7 \mathrm{ra07434d}$

rsc.li/rsc-advances

\section{Lead-germanate glasses: an easy growth process for silver nanoparticles and their promising applications in photonics and catalysis $\uparrow$}

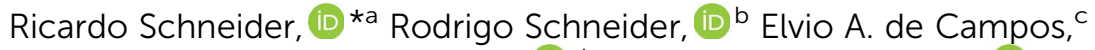 \\ Joaquim Bonfim Santos Mendes, (D) J Jorlandio Francisco Felix (iD ${ }^{\mathrm{e}}$ \\ and Petrus A. Santa-Cruz (iD ${ }^{f}$
}

In this study, we report non-conventional silver nanoparticle growth on the surface of lead-germanate oxide glasses. Thermal annealing at around the glass transition temperature $\left(T_{\mathrm{g}}\right)$ under a nitrogen atmosphere enables the growth of silver thin films on the glass surface. The nanoparticle growth was monitored by scanning electron microscopy (SEM) and UV-visible spectroscopy as a function of the annealing time. The characteristic temperatures were obtained by differential thermal analysis (DTA) and the influence of the $\mathrm{Ag}^{+}$ion content on the glass stability (GS) parameters was evaluated. Additionally, the apparent activation energy of crystallization $(E)$ was calculated. The silver thin films obtained after different annealing times were applied as a substrate for luminescence enhancement of the $\mathrm{Eu}(\mathrm{btfa})_{3} \cdot$ bipy rare earth europium complex. The catalytic activity of the Ag-doped glasses was tested for the reduction of $p$-nitrophenol in the presence of $\mathrm{NaBH}_{4}$. The catalytic performance of the unannealed glass demonstrated an unexpected good efficiency compared with the annealed glass samples.

\section{Introduction}

Lead-germanate glasses exhibit broad potential applications in various fields of industry. ${ }^{1}$ These applications make use of properties such as good thermal stability, high refractive indices, high transmissivity of infrared radiation, strong infrared (IR) cut-off frequencies, and high glass transition temperatures. ${ }^{2-4}$ These distinct properties associated with nanostructured materials grown on the surface of germanate glasses could increase their fields of application. Therefore, nanoparticle/glass structures could be helpful especially for safety applications in cancer diagnosis, photothermal therapy, ${ }^{5}$ bioassays, ${ }^{6}$ contrast agents for optical medical tomography, ${ }^{7}$ Raman spectroscopy ${ }^{\mathbf{8}, 9}$ and catalysis. ${ }^{\mathbf{1 0}}$ Additionally, metallic

${ }^{a}$ Departamento de Química, Universidade Tecnológica Federal Paraná-UTFPR, 85902-490, Toledo, PR, Brazil. E-mail: rschneider@utfpr.edu.br; Tel: +55 453379 6800

${ }^{b}$ Departamento de Quimica, Universidade Federal de São Carlos, 13565-905, São Carlos, SP, Brazil

${ }^{c}$ Departamento de Química, Universidade Estadual do Oeste do Paraná, 85903-000, Toledo, PR, Brazil

${ }^{d}$ Departamento de Física, Universidade Federal de Viçosa, 36570-000, Viçosa, MG, Brazil

${ }^{e}$ Instituto de Física, Universidade de Brasília, 70910-900, Brasília, DF, Brazil ${ }^{f}$ Departamento de Quimica Fundamental, Universidade Federal de Pernambuco-UFPE, 50670-901, Recife, PE, Brazil

$\uparrow$ Electronic supplementary information (ESI) available. See DOI: 10.1039/c7ra07434d nanoparticles in vitreous matrices also influence the luminescence of lanthanide ions. ${ }^{\mathbf{1 1 - 1 6}}$ Mertens and Polman ${ }^{17}$ showed an increase in photoluminescence by two orders of magnitude when $\mathrm{Er}^{3+}$ ions were located in the proximity of an array of silver nanoparticles.

There are several chemical and physical methods to synthesize nanoparticles on glass surfaces. Platinum nanoparticles have been attached to the surface of a glass slide using a chemical reduction method, ${ }^{18}$ Qiu et al. reported the photoreduction of $\mathrm{Ag}^{+}$ions to $\mathrm{Ag}$ atoms in a silicate glass by focusing 120 fs laser pulses ${ }^{\mathbf{1 9}}$ and Mohr et al. produced nanoscale silver particles by $\mathrm{Na} / \mathrm{Ag}$ ion exchange and subsequent thermal treatment in a hydrogen atmosphere. ${ }^{20}$ However, these techniques and conventional physical vapor deposition (PVD) and chemical vapor deposition (CVD) techniques are expensive and require specialized laboratory technicians. ${ }^{21,22}$ On the other hand, the immobilization of nanoparticles through wetchemistry approaches is low cost, but the possibility of surface contamination by reducing agents or chemisorbed stabilizers must be overcome. ${ }^{23}$

In a previous article ${ }^{8}$ we developed a new synthesis process for immobilization of nanoparticles on a glass surface by thermal annealing under a reducing hydrogen atmosphere. The route is based on a one-step growth experiment of metallic nanoparticles on phosphate-based glasses. This simple, inexpensive, and rapid approach has been found to be highly efficient in obtaining nanoparticles with applications in SERS active substrates ${ }^{8,9}$ and catalysis. ${ }^{24}$ 
In this study, we present a silver-doped $\mathrm{PbO}-\mathrm{GeO}_{2}-\mathrm{Al}_{2} \mathrm{O}_{3}$ oxide glass matrix, which provides a catalyst with tailored nanoparticle size, enabling the generation of silver nanoparticles by thermal annealing. Furthermore, the growth of nanoparticles can be achieved without a hydrogen atmosphere. Therefore, the furnace employed to obtain the nanoparticles using this oxide glass matrix is more simple to use in practice. Additionally, this work aims to explore the properties of the metal-enhanced fluorescence of a thermally evaporated volatile rare earth complex on doped silver-lead germanate glasses. Finally, with the use of this method, the samples exhibited significant catalytic activities.

\section{Experimental}

\subsection{Glass synthesis}

The prepared hybrid material was composed of a glass matrix, $\mathrm{PbO}-\mathrm{GeO}_{2}-\mathrm{Al}_{2} \mathrm{O}_{3}$, with silver ions obtained by the inclusion of $\mathrm{Ag}_{2} \mathrm{O}$ as a precursor. Glasses with starting compositions of $\mathrm{PbO} /$ $\mathrm{GeO}_{2}=2$, 0 or $3 \mathrm{~mol} \% \mathrm{Al}_{2} \mathrm{O}_{3}$ and $2.5,1.5$ or 0 mol\% $\mathrm{Ag}_{2} \mathrm{O}$ were prepared using high purity reagents from Sigma-Aldrich. Batches of $2 \mathrm{~g}$ were produced in a covered $\mathrm{Pt} / \mathrm{Au}$ crucible. The mixture was fused for 1 hour in a preheated resistive oven at $950{ }^{\circ} \mathrm{C}$ and the glass samples were obtained by quenching the melt to room temperature in a graphite mold. Table 1 summarizes the nominal starting compositions of the glasses. Silver nanoparticles were obtained on the glass surface by thermal treatment at around the glass transition temperature $\left(T_{\mathrm{g}}\right)$ under a nitrogen $\left(\mathrm{N}_{2}\right)$ gas atmosphere with different annealing times.

\subsection{Sample characterization}

X-ray diffraction (XRD) measurements were performed with a Rigaku diffractometer equipped with $\mathrm{Cu}-\mathrm{K}_{\alpha}$ radiation $(\lambda=$ $1.5418 \AA$ ) in the 5-90 $(\theta-2 \theta)$ range. The glass morphology was investigated using field-emission gun scanning electron microscopy (FEG-SEM).

The glass transition temperature $\left(T_{\mathrm{g}}\right)$, onset crystallization temperature $\left(T_{\mathrm{c}}\right)$, crystallization peak temperature $\left(T_{\mathrm{p}}\right)$, melting temperature $\left(T_{\mathrm{m}}\right)$ and liquidus temperature $\left(T_{1}\right)$ were measured using the glass in powdered form (sieved with a 325 mesh sieve). Crushed samples of $20 \mathrm{mg}$ were placed in an open Pt pan sampler and analyzed by DTA under a constant $\mathrm{N}_{2}$ (5.0 grade) flow $\left(50 \mathrm{~mL} \mathrm{~min}^{-1}\right)$ from $25^{\circ} \mathrm{C}$ to $800{ }^{\circ} \mathrm{C}$, at heating rates $(\alpha)$ of $5,8,10$ and $15{ }^{\circ} \mathrm{C} \min ^{-1}$, using a differential thermal analyzer

Table 1 Nominal starting composition of lead-germanate glasses

\begin{tabular}{llllll}
\hline & \multicolumn{3}{l}{ Concentration in mol (\%) } & \\
\cline { 2 - 4 } Sample & $\mathrm{PbO}$ & $\mathrm{Ge}_{2} \mathrm{O}$ & $\mathrm{Al}_{2} \mathrm{O}_{3}$ & $\mathrm{Ag}_{2} \mathrm{O}$ & \\
\hline $\mathrm{A}$ & 64.67 & 32.33 & 3 & 0 & $0 \% \mathrm{Ag}^{+}$ \\
$\mathrm{B}$ & 63.67 & 31.83 & 3 & 1.5 & $3 \% \mathrm{Ag}^{+}$ \\
$\mathrm{C}$ & 63.00 & 31.50 & 3 & 2.5 & $5 \% \mathrm{Ag}^{+}$ \\
$\mathrm{D}$ & 65.00 & 32.50 & 0 & 2.5 & $5 \% \mathrm{Ag}^{+}$
\end{tabular}

DTA-50 (Shimadzu) with alumina powder as the reference material.

\subsection{Luminescence and rare earth complex deposition}

The nanoparticles were obtained by a bottom-up process with annealing times of $0,2,5$ and 8 minutes. A $60 \mathrm{~nm}$ film of the rare earth luminescent complex $\mathrm{Eu}(\mathrm{btfa})_{3} \cdot \mathrm{bipy}=[\mathrm{btfa}=4,4,4-$ trifluoro-1-phenyl-2,4-butanedione, bipy $=2,2^{\prime}$-dipyridyl $]^{25}$ was deposited over each glass active substrate at $6 \times 10^{-6} \mathrm{mbar}$ by thermal vacuum-evaporation (Auto 306 BOC Edwards Co.).

Scanning by a $1 \mathrm{~m}$ focal length, double grating monochromator (Jobin Yvon U-1000) was applied for luminescence spectra measurements using a $150 \mathrm{~W}$ Xe-Hg lamp as the excitation source. Light detection was performed by a Peltier Cooled RCA C31034 photomultiplier tube.

\subsection{Catalytic measurements}

Solutions of $\mathrm{NaBH}_{4}(1 \mathrm{~mL}, 3 \mathrm{mM})$ and $p$-nitrophenol $(1 \mathrm{~mL}, 0.12$ $\mathrm{mM})$ were shaken for 10 minutes. The characteristic colour of the solution changed from light yellow ( $p$-nitrophenol, $I_{\max }=$ $317 \mathrm{~nm}$ ) to dark yellow ( $p$-nitroenolate, $I_{\max }=400 \mathrm{~nm}$ ). To those solutions, $2 \mathrm{~mL}$ of distilled water was added together with $5 \mathrm{mg}$ of 5\% (mol) Ag-doped lead-germanate glass (sample C, Table 1). A Thermo Scientific spectrometer (model Genesys 10UV Scanning) was used for the measurement of optical absorption during the catalytic testing. The catalytic performance was measured in a quartz cuvette with an absorption pathlength of $1 \mathrm{~cm}$ in the $300-500 \mathrm{~nm}$ wavelength range.

\section{Results and discussion}

Fig. 1(a) shows a schematic diagram of the as-made Ag-doped lead-germanate glass sample and Fig. 1(b) shows the glass sample representation after thermal annealing at the $T_{\mathrm{g}}$ temperature under a $\mathrm{N}_{2}(\mathrm{~g})$ atmosphere, showing the silver nanoparticles, grown from the silver ions, on the glass surface. The top of Fig. 1 displays pictures of glass samples that present the color change from amber $(0 \mathrm{~min})$ to dark brown (after $8 \mathrm{~min}$

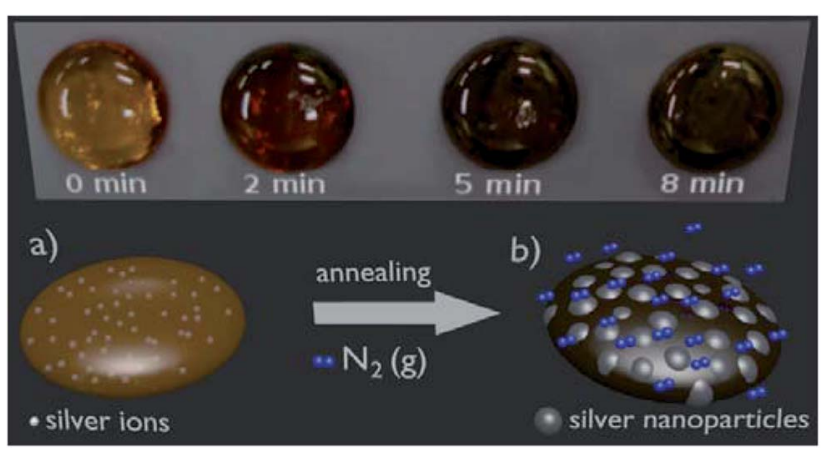

Fig. 1 Top - pictures of samples without annealing and after 2 min to 8 min of annealing. Bottom - a schematic diagram of the bottom-up process for silver nanoparticle growth (a) without thermal annealing and (b) after thermal annealing at the $T_{\mathrm{g}}$ temperature under a $\mathrm{N}_{2}(\mathrm{~g})$ atmosphere. 
of thermal annealing), demonstrating the growth of silver nanoparticles. Different silver ion $\left(\mathrm{Ag}^{+}\right)$concentrations (see Table 1) were used for the glass synthesis. The lead-germanate oxide glasses doped with $\mathrm{Ag}^{+}$ions could be obtained by $\mathrm{Al}^{3+}$ addition (see Fig. S1(a), ESI $\dagger$ ), and a characteristic broad band (halo parameter) of amorphous materials can be observed in the silverless glasses (see Fig. S1(b), ESI $\dagger$ ).

Thermal annealing under a nitrogen atmosphere at the $T_{\mathrm{g}}$ temperature ( $\approx 640 \mathrm{~K}$, Table 2 ) enabled the growth of silver nanoparticles on the glass surface. A characteristic highly reflective appearance was observed after short annealing times and increased with the annealing time (Fig. 1(b)). The silver nanoparticles were formed in a bottom-up process starting with the reduction of $\mathrm{Ag}^{+}$ions inside the glass due to thermal annealing, followed by migration of the $\mathrm{Ag}^{0}$ nanoparticles to the surface. $^{26}$

The thermal annealing of the Ag-doped lead-germanate glasses enabled the growth of silver nanoparticles on the glass surface for the samples doped with (in mol) 3\% (sample B) and $5 \%$ (sample C) silver ions. The silver-doped samples without aluminum ions $\left(\mathrm{Al}^{3+}\right)$ (sample $\mathrm{D}$, Table 1) under thermal annealing showed nanoparticle growth. However, these samples crystallized in the quenching process (see Fig. S2, ESI $\dagger$ ).

\subsection{Glass stability}

Glass stability (GS) is associated with kinetic and thermodynamic factors, and the values of the characteristic temperatures, e.g. $T_{\mathrm{g}}, T_{\mathrm{c}}, T_{\mathrm{p}}, T_{\mathrm{m}}$, and $T_{1}$ are influenced by technical conditions in different ranges by the heating rate $(\alpha) \cdot{ }^{27}$ In the literature there are various methods for determining GS. However, we only used expressions that can be obtained from simple DTA experiments.

By analyzing the characteristic temperatures at various heating rates $(\alpha)$ it is possible to determine the glass kinetics of crystallization. The kinetic study was accomplished with DTA measurements at heating rates of $5,8,10$ and $15{ }^{\circ} \mathrm{C} \mathrm{min}^{-1}$. Fig. 2 shows typical DTA curves of the lead-germanate glasses.

Table 2 Characteristic temperatures for lead-germanate glasses as a function of heating rate $(\alpha)$

\begin{tabular}{|c|c|c|c|c|c|c|}
\hline Sample & $\begin{array}{l}\alpha,{ }^{\circ} \mathrm{C} \\
\min ^{-1}\end{array}$ & $T_{\mathrm{g}}, \mathrm{K}$ & $T_{\mathrm{c}}, \mathrm{K}$ & $T_{\mathrm{p}}, \mathrm{K}$ & $T_{\mathrm{m}}, \mathrm{K}$ & $T_{1}, \mathrm{~K}$ \\
\hline \multirow[t]{4}{*}{ A } & 15 & 667.3 & 705.7 & 720.7 & 972.3 & 982.0 \\
\hline & 10 & 667.0 & 700.9 & 714.0 & 970.0 & 976.1 \\
\hline & 8 & 666.2 & 698.3 & 711.5 & 969.8 & 974.4 \\
\hline & 5 & 663.7 & 694.7 & 705.2 & 969.3 & 973.0 \\
\hline \multirow[t]{4}{*}{ B } & 15 & 657.7 & 675.3 & 685.7 & 970.2 & 988.9 \\
\hline & 10 & 653.8 & 670.9 & 678.3 & 969.4 & 984.5 \\
\hline & 8 & 652.5 & 667.2 & 678.1 & 970.1 & 978.5 \\
\hline & 5 & 648.2 & 664.0 & 672.6 & 969.0 & 971.2 \\
\hline \multirow[t]{4}{*}{$\mathrm{C}$} & 15 & 643.0 & 666.7 & 684.2 & 969.9 & 975.8 \\
\hline & 10 & 641.0 & 661.0 & 673.9 & 969.2 & 973.6 \\
\hline & 8 & 643.3 & 659.2 & 667.6 & 968.5 & 971.7 \\
\hline & 5 & 643.1 & 656.6 & 661.3 & 969.5 & 971.9 \\
\hline
\end{tabular}

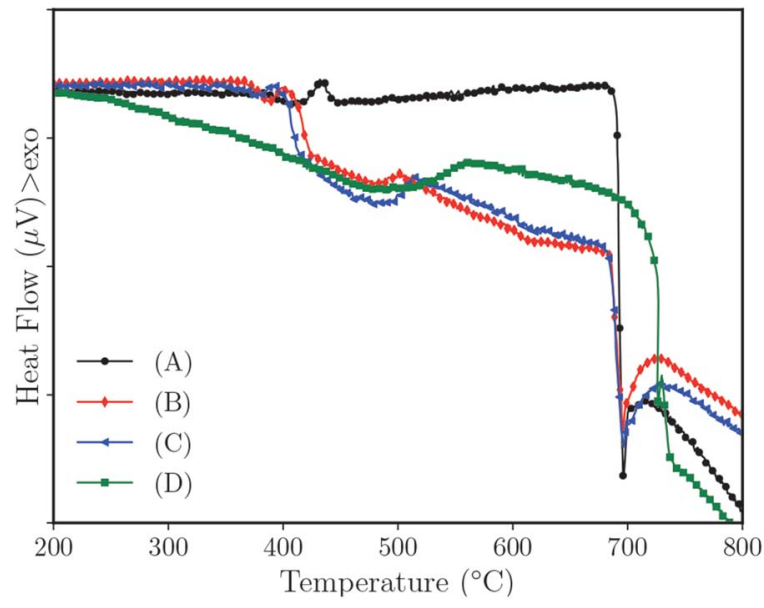

Fig. 2 Differential thermal analysis of the lead-germanate glasses (Table 1) heated at $5^{\circ} \mathrm{C} \mathrm{min}^{-1}$. The curve (D) does not show the $T_{\mathrm{g}}$ temperature. See Table 2 for the characteristic temperatures. DTA curves at the heating rates of 8,10 and $15^{\circ} \mathrm{C} \mathrm{min}-1$ are presented in Fig. S4, ESI.†

A reduction in the characteristic temperatures of the glass system was noticed with the addition of silver ions (Table 2). When the silver ion concentration was increased, the values of $T_{\mathrm{g}}$ and $T_{\mathrm{c}}$ decreased by $\approx 10{ }^{\circ} \mathrm{C}$, an indication that the $\mathrm{Ag}^{+}$ions act as network modifiers. Additionally, the characteristic temperature values shown here are consistent with a previous lead-germanate glass study. ${ }^{28}$

The shift in the characteristic temperatures values, summarized in Table 2, is attributed to: (i) the large shift, resulting from nonisothermal conditions, and, in our case, (ii) the formation of silver nanoparticles on the glass surface (Fig. 1). For a nonisothermal DTA process the following equation can be derived: ${ }^{29,30}$

$$
\ln \left(\frac{T_{\mathrm{p}}^{2}}{\alpha}\right)=\ln \left(\frac{E}{R \nu}\right)+\frac{E}{R T_{\mathrm{p}}},
$$

where $R$ is the universal gas constant, $T_{\mathrm{p}}$ is the crystallization peak temperature for the scan rate $\alpha$ (Table 2), $\nu$ is the preexponential factor and $E$ is the activation energy. As pointed out by Poulain, ${ }^{31}$ the activation energy shows an inverse relationship with the glass stability (GS) and should be best named as the apparent activation energy. Therefore, lower values indicate a higher glass stability.

Fig. 3 shows the $\ln \left(\frac{T_{\mathrm{p}}{ }^{2}}{\alpha}\right)$ against $1 / T_{\mathrm{p}}$ plot for the Ag-doped and undoped glasses. Table 3 shows the values of $E$ and $\nu$ obtained using linear regression of the curves of Fig. 3. These values indicate that sample $\mathrm{C}$, with $5 \% \mathrm{Ag}^{+}$ions, is the most stable sample if the activation energy is considered. Therefore, the increase in the concentration of silver ions generated more stable glasses.

Duan et $a l .{ }^{27}$ propose the following criterion for GS:

$$
k_{\mathrm{D}}(T)=\nu \mathrm{e}^{-\frac{E D}{R T}}
$$




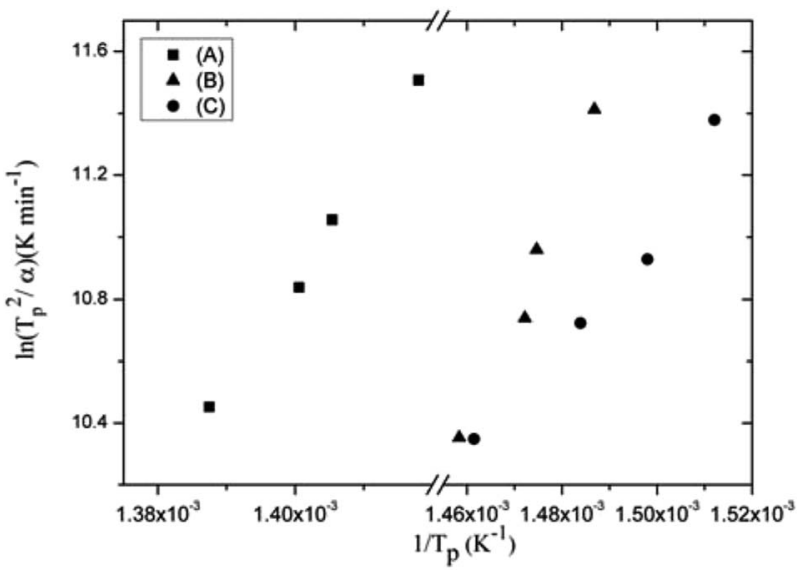

Fig. 3 Graph of $\ln \left(\frac{T_{\mathrm{p}}{ }^{2}}{\alpha}\right)$ against $1 / T_{\mathrm{p}}$ for the lead-germanate glass samples A, B and C (see Table 1 ).

Table 3 Kinetic parameters for the lead-germanate glasses

\begin{tabular}{llll}
\hline Sample & $E, \mathrm{~kJ} \mathrm{~mol}^{-1}$ & $\nu, \mathrm{min}^{-1}$ & $R^{2}$ \\
\hline A & 289.57 & $9.973 \times 10^{20}$ & 0.99 \\
B & 311.93 & $7.173 \times 10^{23}$ & 0.96 \\
C & 162.90 & $1.781 \times 10^{12}$ & 0.95
\end{tabular}

Table 4 Values of stability $k_{\mathrm{D}}$ proposed by Duan et al. ${ }^{27}$ with $T=298 \mathrm{~K}$

\begin{tabular}{llll}
\hline$\alpha,{ }^{\circ} \mathrm{C} \min ^{-1}$ & $k_{\mathrm{D}}(\mathrm{A})\left(\times 10^{19}\right)$ & $k_{\mathrm{D}}(\mathrm{B})\left(\times 10^{22}\right)$ & $k_{\mathrm{D}}(\mathrm{C})\left(\times 10^{11}\right)$ \\
\hline 15 & 1.548 & 3.851 & 1.580 \\
10 & 2.583 & 7.054 & 3.049 \\
8 & 2.508 & 3.672 & 5.660 \\
5 & 5.567 & 7.117 & 9.266
\end{tabular}

where,

$$
D=\frac{T_{\mathrm{c}}\left(T_{\mathrm{p}}-T_{\mathrm{c}}\right)}{T_{\mathrm{m}}\left(T_{\mathrm{m}}-T_{\mathrm{g}}\right)}
$$

which includes the kinetic and thermodynamic factors by means of the correction factor $(D)$. The $k_{\mathrm{D}}(T)$ criterion indicates the following order $\mathrm{C}>\mathrm{A}>\mathrm{B}$ for glass stability (Table 4), like the GS order observed with the activation energy $(E)$ (Table 3 ).

\subsection{Morphological analysis}

The surface morphology and growth of the silver nanoparticles formed by the bottom-up process (Fig. 1) were monitored by scanning electron microscopy (SEM). The SEM images did not show silver nanostructures on the as-made silver-doped glass surface without annealing (Fig. 4(a)). However, after annealing at $T_{\mathrm{g}}$ under a nitrogen atmosphere, spherical-like silver nanoparticles could be seen, as shown in Fig. 4(b). The increase in the thermal annealing time allows the silver ions to migrate to the glass surface, where they are reduced to form silver atoms/ clusters. Additionally, the surface migration and subsequent
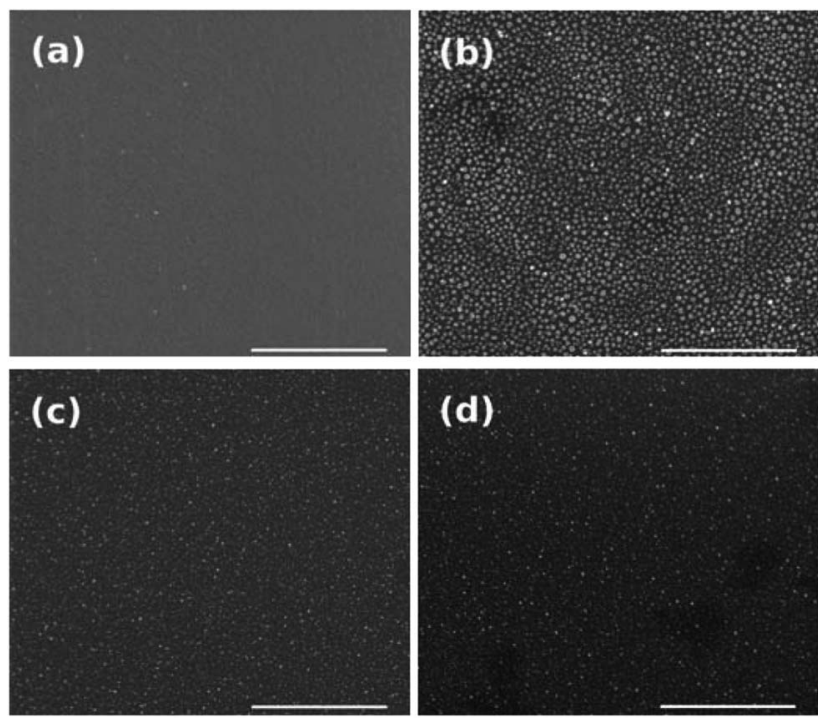

Fig. 4 SEM images of silver-doped glasses (sample $C$ ) annealed at $T_{\mathrm{g}}$ for (a) 0 min (unannealed), (b) $2 \mathrm{~min}$, (c) $5 \mathrm{~min}$, and (d) $8 \mathrm{~min}$. Scale bar $=1 \mu \mathrm{m}$.

coalescence of the silver nanoparticles generates a continuous silver film on the glass surface, as demonstrated by the lower contrast shown in Fig. 4(c) and (d). This effect can also be corroborated by the broad surface plasmon resonance (SPR) band shown in the UV-vis spectrum (see Fig. 5(a)).

The growth of silver nanoparticles on the surface of the lead oxide system demonstrates its fast growth kinetics compared with glasses considered more stable, e.g., the lead oxyfluoride glass system, where more than three hours of thermal annealing are necessary to observe a continuous metallic thin film. ${ }^{25}$ Indeed, molecular dynamics simulations of halide glasses showed that the silver atoms aggregate into small clusters,

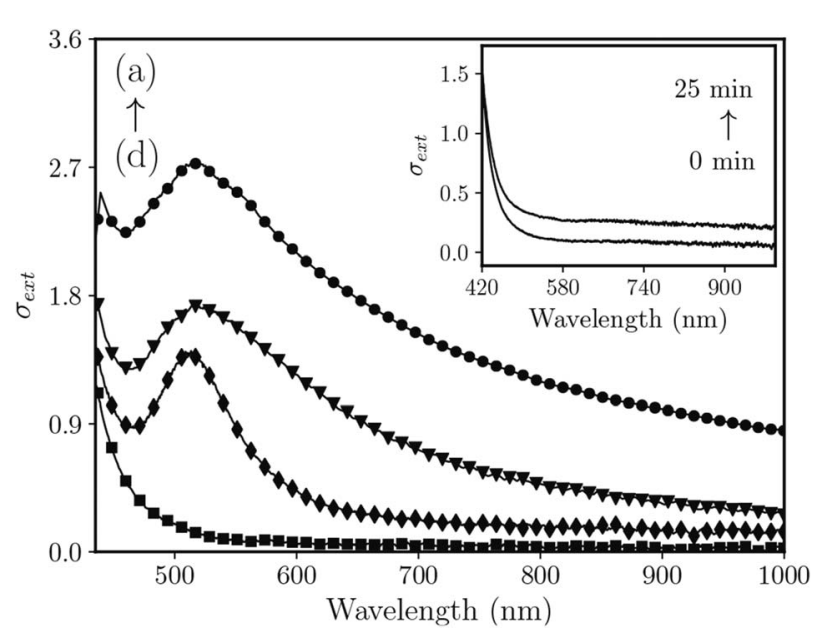

Fig. 5 Extinction spectra of $5 \% \mathrm{Ag}^{+}$-doped lead-germanate (sample C, Table 1) glasses annealed at $T_{\mathrm{g}}$ for (a) $8 \mathrm{~min}$, (b) $5 \mathrm{~min}$, (c) $2 \mathrm{~min}$, and (d) unannealed sample. Inset: undoped glass (sample A) before and after annealing at $T_{\mathrm{g}}$. All annealing experiments were performed under $50 \mathrm{~mL} \mathrm{~min}^{-1} \mathrm{~N}_{2}$ flow. 
supporting the mechanism of aggregation, nucleation and diffusion to the glass surface. ${ }^{26}$

\subsection{Optical and luminescence properties}

The lead-germanate glass doped with $5 \%$ silver ions had the greatest glass stability (GS) (Section 3.1) and due to this it was chosen for rare earth complex deposition. Fig. 5 shows the extinction spectra of the doped glasses with $5 \% \mathrm{Ag}^{+}$ions at different annealing times under nitrogen flow. As shown by the DTA experiment (Fig. 2) and SEM images (Fig. 4), thermal annealing enables the formation of metallic silver on the glass surface. The optical spectrum shows an intense SPR peak centered at $\approx 515 \mathrm{~nm}$ when the Ag-doped glass was annealed for 2 minutes (Fig. 5(c)). The presence of silver nanoparticles was confirmed by a weak XRD peak at $2 \theta=38.1$ (111) (see Fig. S3, ESI $\dagger$ ). The subsequent increase in the annealing time (Fig. 5(a) and (b)) resulted in a broadening in the SPR peak with a simultaneous rise in the scattered light intensity due to the nanoparticle size increase.

Consequently, light reflection on the silver thin film was observed over the full range of the spectra. ${ }^{32}$ With long annealing times ( $>8 \mathrm{~min}$ ) a highly reflective silver nanofilm was obtained and the absorption spectrum acquisition is not technically feasible to obtain, which is expected due to the increase in the amount of silver on the glass surface. The SPR peak is absent in the unannealed doped sample spectrum (Fig. 5(d)). As expected, the thermal annealing of the undoped glass (inset of Fig. 5) provides a baseline drift, but without the characteristic SPR peak of the silver nanoparticles.

The luminescence increase of $\mathrm{Eu}^{3+}$-doped glasses containing silver nanoparticles was reported earlier by Malta and coworkers ${ }^{\mathbf{1 1}}$ as an interaction between the $4 \mathrm{f}$ electrons and surface plasmons (SPs) of silver nanoparticles inside the glass matrix. The silver nanoparticles obtained on the lead glass surface were

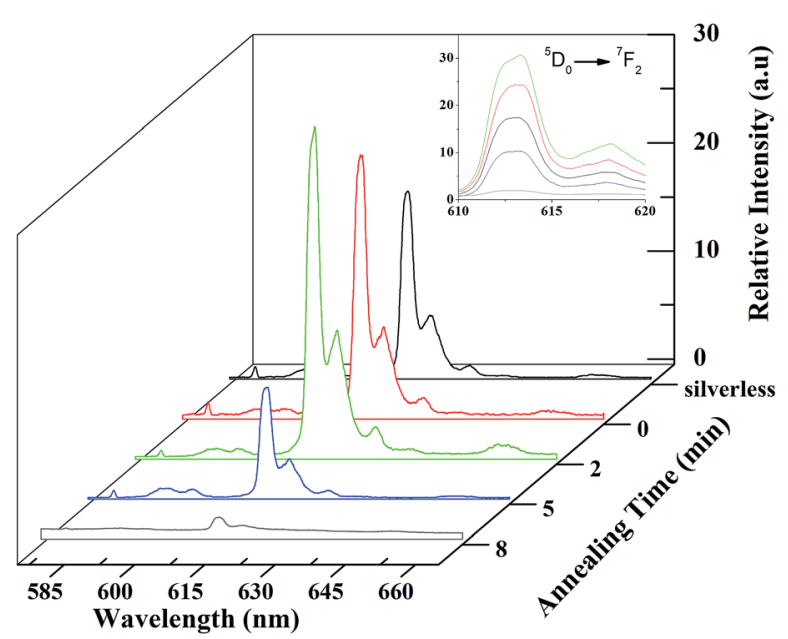

Fig. 6 Luminescence spectra of the Eu(btfa) 3 . bipy complex, deposited over the silver nanoparticles, under UV excitation $(365 \mathrm{~nm})$ and normalized for ${ }^{5} D_{0}-{ }^{7} F_{1}$ (centered at $\approx 595 \mathrm{~nm}$ ) transition. The inset graph (overlay spectra) shows the luminescence intensity change in the $610-620 \mathrm{~nm}$ region $\left(\mathrm{Eu}^{3+},{ }^{5} \mathrm{D}_{0} \rightarrow{ }^{7} \mathrm{~F}_{2}\right)$. covered with a $\mathrm{Eu}(\mathrm{btfa})_{3} \cdot$ bipy thin film deposited by thermal evaporation. Under excitation at a wavelength of $365 \mathrm{~nm}$, the rare earth complex showed red centered luminescence $\left(\mathrm{Eu}^{3+}\right.$, $\left.{ }^{5} \mathrm{D}_{0} \rightarrow{ }^{7} \mathrm{~F}_{2}\right) \cdot{ }^{33,34}$ Fig. 6 shows the luminescence spectra, normalized for ${ }^{5} \mathrm{D}_{0}-{ }^{7} \mathrm{~F}_{1}$ transition, of the $\mathrm{Eu}(\mathrm{btfa})_{3} \cdot$ bipy thin film as a function of the thermal annealing at $T_{\mathrm{g}}$. The luminescence increased from the silverless sample to the doped glass which was thermally annealed for $2 \mathrm{~min}$, before luminescence quenching occurred drastically, with the luminescence reaching a minimum value for the glass annealed for $8 \mathrm{~min}$. Continuous silver films (mirror-like properties) reflect electromagnetic radiation rather than generate surface plasmons. Therefore, the local electric field of isolated nanoparticles and the interparticle distance may contribute to the effective fluorescence. ${ }^{7,35,36}$ Thus, as an increase in the annealing time favors the formation of a continuous silver thin film (Fig. 5(a) and (b)), the local electric field decreases and, consequently, so does the luminescence intensity. ${ }^{37}$

\subsection{Catalyst performance}

Glasses can be made by standard procedures such as the conventional melt quenching technique. Normally, the application of glasses in catalytic processes is limited to support materials. However, glasses with catalytic capabilities are desirable due to the simple and reliable scaling up of their synthesis. The silver nanoparticles obtained on the lead-germanate glass surface were applied in the $p$-nitrophenol/ $\mathrm{NaBH}_{4}$ catalytic reaction. The presence of a metallic catalyst is essential for the reaction's progress, which can be monitored by changes in the initial absorbance $\left(A_{0}\right)$ intensity at $400 \mathrm{~nm} .^{38}$

Fig. 7 shows the normalized absorbance $\left(A / A_{0}\right)$ for catalytic reactions with the annealed doped glasses (sample $\mathrm{C}$, Table 1) and the unannealed Ag-doped glass sample. Fig. 7(a), (b) and

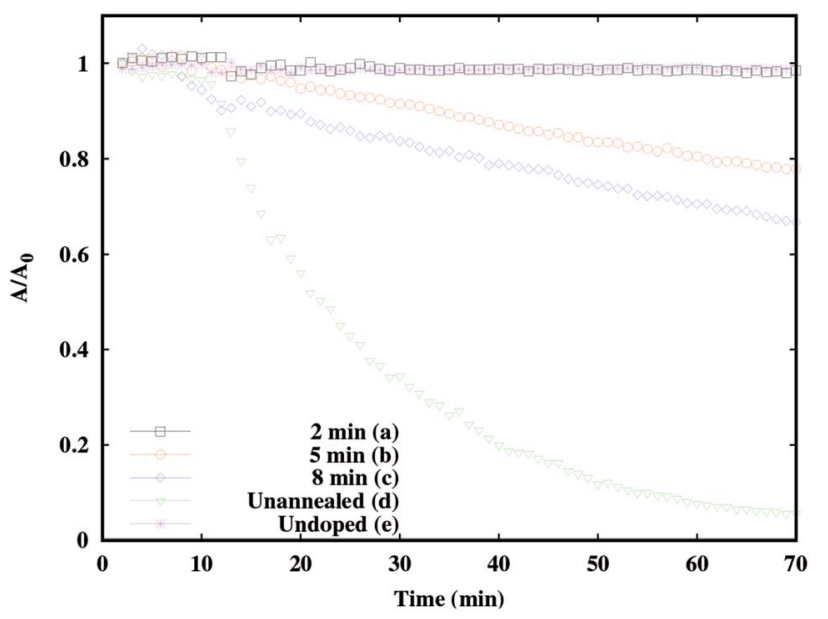

Fig. 7 Catalytic performance of the $5 \% \mathrm{Ag}^{+}$-doped (sample C, Table 1) and undoped lead-germanate glasses. Normalized absorbance $A / A_{0}$ versus time (min) plots for the samples annealed at $T_{\mathrm{g}}$ for (a) $2 \mathrm{~min}$, (b) $5 \mathrm{~min}$, and (c) $8 \mathrm{~min}$, and the (d) unannealed and (e) undoped (sample A, Table 1) samples. All annealing experiments were performed under $50 \mathrm{~mL} \min ^{-1} \mathrm{~N}_{2}$ flux. 
(c) show the catalytic performance of Ag-doped glass annealed for $2 \mathrm{~min}, 5 \mathrm{~min}$ and $8 \mathrm{~min}$, respectively. It was noted that when the annealing time was increased from 2 min (Fig. 7(a)) to $8 \mathrm{~min}$ (Fig. 7(c)), the catalytic efficiency was enhanced. However, the as-prepared doped glass showed superior catalytic activity without any necessity for annealing for the growth of nanoparticles (Fig. 7(d)). The enhancement in the catalytic activity is consistent with the increase in the quantity of silver nanoparticles on the glass surface for the Ag-annealed glasses. The increase in annealing time enhanced the catalytic activity, but did not achieve complete conversion, whereas the unannealed Ag-doped glass completed the reaction in $\approx 60 \mathrm{~min}$. Commonly, the catalytic reduction of $p$-nitrophenol by sodium borohydride proceeds in the presence of a metal catalyst. ${ }^{39-42}$ The silverless sample A (Table 1 ) had no catalytic activity for the reduction of $p$-nitrophenol by $\mathrm{NaBH}_{4}$ (Fig. 7(e)). The absence of catalytic activity enabled us to infer, in this specific situation, the important role of the doping of the glass with silver ions and the formation of metallic silver in the reaction proceeding.

The catalytic performance of the unannealed glass (Fig. 7(d)) is attributed to in situ silver nanoparticle formation on the powdered glass surface due to $\mathrm{H}^{-}$ions. The in situ reduction of metallic ions by $\mathrm{H}^{-}$ions has been extensively studied in the literature ${ }^{\mathbf{4 0 , 4 1 , 4 3}}$ - in other words, new metallic nanostructures are formed on the glass surface. The adsorbed hydride ions, formed on the fresh metallic layer, can be transferred to the $p$-nitroenolate ions and consequently the peak at $400 \mathrm{~nm}$ gradually reduces. ${ }^{40,44}$ In this way, the Ag-doped lead-germanate glasses act as in situ active matrices for supported synthesis of silver nanostructures.

\section{Conclusion}

In summary, a non-conventional methodology for the synthesis and immobilization of silver nanoparticles on to glass surfaces by a bottom-up process was reported. The bottom-up process was thermally activated and accomplished in short times under a nitrogen atmosphere, without the necessity of reducing reagents or additional steps for nanoparticle immobilization. The role of $\mathrm{Al}^{3+}$ ions in lead-germanate domain glasses was demonstrated and we could see only a broad band, characteristic of amorphous glassy materials, when the aluminium ions were added. By changing the precursor reagents it was possible to obtain Ag-doped glasses, capable of the fast growth of silver nanoparticles on their surface, by a bottom-up process. The silver nanoparticles obtained on the lead glass surface were applied as a substrate for luminescence enhancement of rare earth europium complex thin films. The catalytic activity of the glasses was successfully utilized in the catalytic $p$-nitrophenol reduction by sodium borohydride. The glasses without nanoparticles on their surfaces exhibited considerably better performance compared with the glasses with nanoparticles, this behaviour being attributed to in situ silver reduction. Additionally, this methodology for autosupported nanoparticle synthesis has potential applications in SERS substrates, catalysis and photonic devices.

\section{Conflicts of interest}

There are no conflicts to declare.

\section{Acknowledgements}

The authors are grateful to the Instituto de Tecnologia de Pernambuco (ITEP) for XRD measurements. Furthermore, we thank the Brazilian agency CNPq, CAPES, FAPDF (193.001.078/ 2015) and FUNASA (25100.011.260/2014-17) for financial support and the research scholarship. The penultimate author is also grateful to DIRPE-UnB for financial support. We thank Matheus H. Lazzarin for his manuscript reading.

\section{References}

1 H. T. Munasinghe, A. Winterstein-Beckmann, C. Schiele, D. Manzani, L. Wondraczek, S. A. Vahid, T. M. Monro and H. Ebendorff-Heidepriem, Opt. Mater. Express, 2013, 3, 1488.

2 G. Bai, L. Tao, K. Li, L. Hu and Y. H. Tsang, Opt. Mater., 2013, 35, 1247-1250.

3 V. V. Gowda, Phys. B, 2015, 456, 298-305.

4 A. Witkowska, B. Sikora, K. Trzebiatowski and J. Rybicki, J. Non-Cryst. Solids, 2006, 352, 4356-4361.

5 X. Huang and M. A. El-Sayed, J. Adv. Res., 2010, 1, 13-28.

6 M. H. Chowdhury, K. Ray, K. Aslan, J. R. Lakowicz and C. D. Geddes, J. Phys. Chem. C, 2007, 111, 18856-18863.

7 C. D. Geddes, H. Cao, I. Gryczynski, Z. Gryczynski, J. Fang and J. R. Lakowicz, J. Phys. Chem. A, 2003, 107, 3443-3449.

8 R. Schneider, J. F. Felix, L. G. Moura and P. C. Morais, J. Mater. Chem. C, 2014, 2, 9021-9027.

9 A. J. Pereira, J. P. Gomes, G. F. Lenz, R. Schneider, J. A. Chaker, P. E. N. de Souza and J. F. Felix, J. Phys. Chem. $C, 2016,120,12265-12272$.

10 A. Cao, R. Lu and G. Veser, Phys. Chem. Chem. Phys., 2010, 12, 13499.

11 O. Malta, P. Santa-Cruz, G. D. Sá and F. Auzel, J. Lumin., 1985, 33, 261-272.

12 O. Malta, P. Santa-Cruz, G. D. Sá and F. Auzel, Chem. Phys. Lett., 1985, 116, 396-399.

13 O. Malta, Phys. Lett. A, 1986, 114, 195-197.

14 O. Malta and M. C. dos Santos, Chem. Phys. Lett., 1990, 174, 13-18.

15 M. Couto, O. Malta and G. de Sá, J. Alloys Compd., 1992, 180, 215-221.

16 G. D. Sá, O. Malta, W. D. Azevêdo and H. Dexpert, J. LessCommon Met., 1989, 148, 387-391.

17 H. Mertens and A. Polman, Appl. Phys. Lett., 2006, 89, 211107.

18 M.-H. Yang, F.-L. Qu, Y.-S. Lu, G.-L. Shen and R.-Q. Yu, Talanta, 2008, 74, 831-835.

19 J. Qiu, M. Shirai, T. Nakaya, J. Si, X. Jiang, C. Zhu and K. Hirao, Appl. Phys. Lett., 2002, 81, 3040-3042.

20 C. Mohr, M. Dubiel and H. Hofmeister, J. Phys.: Condens. Matter, 2000, 13, 525-536.

21 I. Pastoriza-Santos and L. M. Liz-Marzán, J. Mater. Chem., 2008, 18, 1724. 
22 O. Masala and R. Seshadri, Annu. Rev. Mater. Res., 2004, 34, 41-81.

23 T. Tsuji, K. Iryo, N. Watanabe and M. Tsuji, Appl. Surf. Sci., 2002, 202, 80-85.

24 G. F. Lenz, R. A. Bini, T. P. Bueno, R. J. de Oliveira, J. F. Felix and R. Schneider, J. Mater. Sci., 2017, 52, 6635-6646.

25 R. Schneider, W. H. Schreiner and P. A. Santa-Cruz, J. Lumin., 2013, 136, 172-177.

26 S. R. Santana, F. S. L. Borba, G. G. Pedrosa, P. A. S. Cruz and R. L. Longo, J. Comput.-Aided Mater. Des., 2006, 12, 101-110.

27 R.-G. Duan, K.-M. Liang and S.-R. Gu, J. Eur. Ceram. Soc., 1998, 18, 1131-1137.

28 V. Sigaev, I. Gregora, P. Pernice, B. Champagnon, E. Smelyanskaya, A. Aronne and P. Sarkisov, J. Non-Cryst. Solids, 2001, 279, 136-144.

29 H. E. Kissinger, Anal. Chem., 1957, 29, 1702-1706.

30 J. Llópiz, M. Romero, A. Jerez and Y. Laureiro, Thermochim. Acta, 1995, 256, 205-211.

31 M. Poulain, Thermochim. Acta, 1996, 280-281, 343-351.

32 S. Pillai, K. R. Catchpole, T. Trupke and M. A. Green, J. Appl. Phys., 2007, 093105, 101.

33 C. Gameiro, E. da Silva, S. Alves, G. de Sá and P. Santa-Cruz, J. Alloys Compd., 2001, 323-324, 820-823.
34 O. Malta, H. Brito, J. Menezes, F. e Silva, S. Alves, F. Farias and A. de Andrade, J. Lumin., 1997, 75, 255-268.

35 K.-H. Su, Q.-H. Wei, X. Zhang, J. J. Mock, D. R. Smith and S. Schultz, Nano Lett., 2003, 3, 1087-1090.

36 W. Rechberger, A. Hohenau, A. Leitner, J. Krenn, B. Lamprecht and F. Aussenegg, Opt. Commun., 2003, 220, 137-141.

37 J. R. Lakowicz, Anal. Biochem., 2005, 337, 171-194.

38 P. Zhao, X. Feng, D. Huang, G. Yang and D. Astruc, Coord. Chem. Rev., 2015, 287, 114-136.

39 Z. D. Pozun, S. E. Rodenbusch, E. Keller, K. Tran, W. Tang, K. J. Stevenson and G. Henkelman, J. Phys. Chem. C, 2013, 117, 7598-7604.

40 A. K. Sasmal, S. Dutta and T. Pal, Dalton Trans., 2016, 45, 3139-3150.

41 S. Das and S. Jana, Dalton Trans., 2015, 44, 8906-8916.

42 X. Kai Kong, Z. Yuan Sun, M. Chen, C. Le Chen and Q. Wang Chen, Energy Environ. Sci., 2013, 6, 3260.

43 Y. Lin, Y. Qiao, Y. Wang, Y. Yan and J. Huang, J. Mater. Chem., 2012, 22, 18314.

44 S. Wunder, Y. Lu, M. Albrecht and M. Ballauff, ACS Catal., 2011, 1, 908-916. 